Ana Ruth dos Santos Chaves

Universidade Federal do Pará, Belém, PA, Brasil

Roberta Rowsy Amorim de Castro

Universidade Federal do Pará, Belém, PA, Brasil

Andreia de Menezes

Universidade Federal do Pará, Belém, PA, Brasil

\title{
A busca pela ascensão feminina no PDS Virola Jatobá, Anapu-PA
}

Resumo: Esta pesquisa teve como objetivo analisar o papel das mulheres no PDS Virola Jatobá, Anapu-Pará, sua importância e representatividade nas atividades produtivas, econômicas e sociais, bem como descrever como está se dando a busca pela ascensão feminina através do associativismo. Foram entrevistadas 18 mulheres agricultoras e foi constatado que estas participam dos processos de trabalho nos sistemas de cultivo, criações e extrativista. Em relação às atividades anexas e rendas extras, todas as entrevistadas contribuem na renda mensal de suas famílias. As mulheres do PDS exercem papel coletivo relevante ao se organizarem em associações de gênero e outras, evidenciando a busca por inserção em vários cenários. Essa ałuação colabora para que se reconheçam como trabalhadoras e não somente como ajudantes. Palavras-Chave: Agricultura Familiar; mulheres agricultoras; relações de gênero; trabalho feminino

\section{Introdução}

A agricultura familiar é a principal geradora de postos de trabalho no meio rural brasileiro (Maria de Nazareth Baudel WANDERLEY, 1996). Nesta área, mesmo sendo grande a presença do trabalho feminino, há um enorme contingente de mulheres que não recebe nenhum rendimento pelo seu trabalho. Pesquisas indicam que mulheres que se declararam trabalhadoras rurais se concentram nas categorias de trabalho de produção para o próprio consumo e trabalho não remunerado (BRASIL, 2008).

\section{(c) (7)}

Esta obra está sob licença Creative Commons. 
Sobre esse cenário, Flávia Maria GALIZONI e Eduardo Magalhães RIBEIRO (2004) mencionam em seus estudos que as mulheres que trabalham na agricultura têm sua identidade definida por sua atuação nas atividades domésticas, sendo que estas não são vistas como trabalho. Para os autores, essa situação reflete a "invisibilidade" do trabalho feminino e o não reconhecimento das trabalhadoras rurais, dificultando o seu acesso aos direitos previstos em lei, excluindo-as das políticas de desenvolvimento. Com pensamento semelhante, Rosineide de Lourdes Meira CORDEIRO (2007) destaca que a participação produtiva feminina é pouco mencionada nos estudos sobre agricultura familiar devido a uma rígida divisão sexual do trabalho pouco favorável às mulheres, ocasionando, assim, a invisibilidade do seu potencial produtivo na agricultura familiar e uma subestimação da sua participação econômica.

Em diversas pesquisas nota a reprodução do discurso que a mulher não trabalha, ou seja, seus afazeres domésticos, a responsabilidade sobre os filhos, cuidados com pequenos animais (aves, gado de leite e suínos), cultivo e manutenção de hortas são vistos como "leve" ou "ajuda", termos que foram citados por autores como Maria Ignez Silveira PAULILO (1987) e Valdete BONI (2006). Este pensamento é mantido mesmo quando ela realiza outros trabalhos equivalentes ou iguais aos realizados pelo homem (Beatriz Maria Alásia de HEREDIA, 1979; Ellen F. WOORTMANN, Klass WOORTMANN, 1997).

Desse modo, apesar da evolução de discussões em prol da igualdade de gênero, ainda se percebe a não valorização do trabalho feminino. As mulheres ocupam uma posição subordinada e seu trabalho, como já mencionado, é tratado como 'ajuda'. Entretanto, considera-se que "a divisão sexual dos papéis, portanto, nada tem de natural: é uma construção social" (Xavier ARNAULD DE SARTRE et al., 2013, p. 108).

Nessa conjuntura onde as mulheres agricultoras estão, de certa forma, em constante busca por reconhecimento dos seus direitos e da importância das suas funções para a reprodutibilidade e sustentabilidade de suas famílias, esta pesquisa teve como objetivo analisar o papel das mulheres no Projeto de Desenvolvimento Sustentável - PDS Virola Jatobá, município de Anapu-Pará, sua importância e representatividade nas atividades produtivas, econômicas e sociais, e descrever como está se dando a busca pela ascensão feminina através do associativismo.

\section{O PDS Virola Jatobá como locus de estudo}

O município de Anapu teve origem com a abertura da rodovia BR-230 (Transamazônica) na década de 1970' e recebeu imigrantes de diversas partes do país, na maioria nordestinos e sulistas que foram para região através de programas governamentais que prometiam terras e melhores condições de vida (Sérgio SAUER, 2005). Entretanto, o mesmo só foi oficializado como município pela Lei Estadual n 5.929 de 1995 (PARÁ, 1995).

\footnotetext{
' A partir da década de 1970, a região amazônica passou a ser fonte de intensas políticas de povoamento, ocasionando diversas consequências ambientais como: queimadas, grandes áreas desmatadas e/ou com pastagens extensivas, degradação do solo resultando em assoreamento de rios e igarapés. Esses cenários são resultantes, entre outros fatores, do incentivo governamental a essas práticas predatórias de exploração, onde a motosserra era símbolo do domínio sobre a natureza, às margens da rodovia Transamazônica (Ariovaldo Umbelino de OLIVEIRA, 1988)
}

2 Revista Estudos Feministas, Florianópolis, 26(1): e42742 
Parte da ocupação do município se deu de forma desordenada, ${ }^{2}$ pela abertura de uma nova fronteira por grileiros, ampliando as ações de apropriação ilegal e desmatamento descontrolado que resultou graves conflitos agrários, envolvendo novos e antigos ocupantes. Esses conflitos tornaram-se mundialmente conhecidos com o assassinato da irmã Dorothy Stang $^{3}$ em 2005.

Grileiros, fazendeiros e movimentos sociais lutaram arduamente pela posse da terra e o direito de viver nela. Após anos de conflitos, o Governo Federal, através da Portaria/INCRA/ $\mathrm{P} \mathrm{n}^{\circ}$ 477, em 04 de novembro de 1999 - regulamentada pela Portaria/INCRA/P n 1.032 de 25 de outubro de 2000 , criou, sob as reivindicações da missionária norte-americana Dorothy Stang e dos movimentos sociais da região, o Projeto de Desenvolvimento Sustentável Virola Jatobá. Entretanto, o PDS foi oficializado somente em 13 de dezembro de 2002, através da Portaria INCRA/SR-01 n० 39, como um novo modelo de reforma agrária para a região. Por meio dessa Portaria, os beneficiários assumiram o compromisso de respeitar a legislação ambiental e seguir critérios de sustentabilidade, onde as famílias assentadas dispõem de área 100 ha, sendo 20 ha para o uso alternativo na agricultura e os 80 ha restantes devem ficar para conservação ambiental.

O mesmo está situado nas coordenadas $03^{\circ} 04^{\prime} 58^{\prime \prime} S$ de latitude e $51^{\circ} 23^{\prime} 11^{\prime \prime} \mathrm{W}$ de longitude a $45 \mathrm{~km}$ da sede do município de Anapu - sentido Anapu-Altamira (Figura 1). Segundo os dados da Relação de Beneficiários (RB) de 2014 do Instituto de Colonização de Reforma Agrária (INCRA), o PDS Virola Jatobá possui uma área de 32.345 ha dividida em quatro vicinais: 107, 120, 129 (Mutum) e 132, onde existem 114 assentados, 28 não assentados, ${ }^{4} 04$ lotes comunitários ${ }^{5}$ e 14 lotes vagos.

Para garantir e efetivar o direito e a participação das trabalhadoras rurais do Programa Nacional de Reforma Agrária (PNRA), o INCRA, através da Inscrição Normativa n 38 de 13 de março de 2007, dispõe, no artigo $2^{\circ}$ do capítulo Il, parágrafos $\S 1$ e $§ 2$, sobre a obrigatoriedade dos candidatos (mulher e homem) na Relação de Beneficiários que identifica a unidade familiar nos casos de união estável e como será realizada a comprovação para garantir a participação das mulheres independentemente do seu estado civil. No Capítulo III, artigo $5^{\circ}$, sobre a condição da mulher assentada nos projetos de reforma agrária, dispõe que: "nos casos de dissolução do casamento ou da união estável será assegurada a permanência da mulher como detentora do lote ou parcela, desde que os filhos estejam sob sua guarda" (BRASIL, 2007).

\section{Metodologia}

A pesquisa de campo teve a duração de quatro meses, de outubro de 2014 a fevereiro de 2015. Durante esse período foram realizadas oito visitas ao PDS, onde, a partir de

\footnotetext{
2 "O Estado na região atuava sob a figura do INCRA, que se propôs a promover uma colonização à beira da rodovia Transamazônica, estabelecendo loteamentos para aqueles que chegavam à região. No entanto, com o passar do tempo, em decorrência da falta de capacidade logística e operacional do INCRA que não teve mais condições de monitorar e subsidiar a grande quantidade de migrantes que chegavam, visto que além dos migrantes subsidiados pelo governo, começaram a chegar à região outras famílias, que atraídas pela grande quantidade de terras disponíveis, vieram por conta própria, não recebendo qualquer tipo de incentivo do Estado, processo que foi chamado de migração espontânea" (Roberta Rowsy Amorim de CASTRO, 2013, p. 59) 3 "Dorothy Stang, americana naturalizada brasileira, 73 anos. Missionária da congregação NotreDame trabalhava no Pará desde 1966 e era reconhecida defensora das causas ambientais, agrárias e de direitos humanos, enfrentando oposição de madeireiros e fazendeiros" (SAUER, 2005, p. 91).

${ }^{4}$ Agricultores que ainda não estão na lista de RB, mas já residem no lote.

${ }^{5}$ Lotes de uso coletivo que podem ser utilizados para implantações de Unidades Demonstrativas (UDs), onde está localizado o barracão comunitário das vicinais.
} 


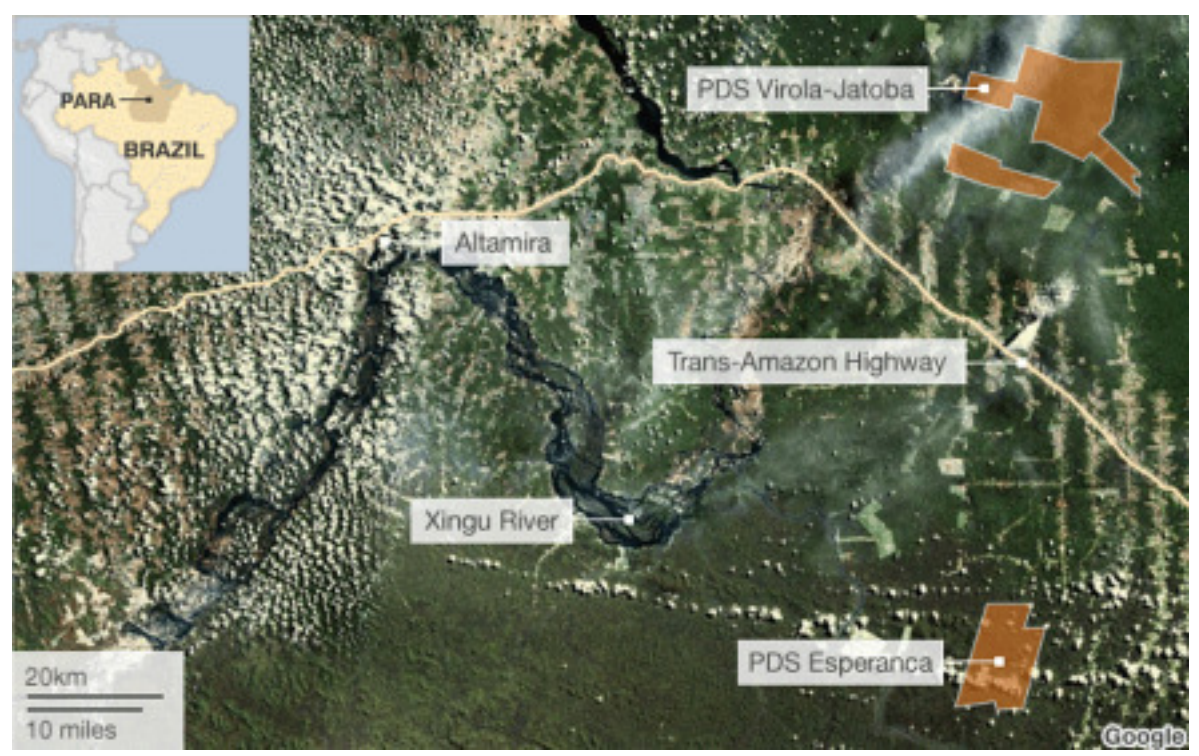

Figura 1 - Localização espacial do PDS Virola Jatobá.

Fonte: http://www.bbc.com/news/world-latin-america-20408238. Publicada em 29/1 1/2012.

observação participante, ${ }^{6}$ observação direta ${ }^{7}$ e conversas informais, foram levantados dados necessários à pesquisa. Nas visitas às vicinais, diversas atividades foram acompanhadas, das quais se destacam a eleição da diretoria da Associação Virola Jatobá e reuniões do grupo de mulheres. A convivência e interação durante essas atividades permitiu a criação de laços de amizade entre a pesquisadora e as agricultoras pesquisadas, facilitando o repasse de informações sobre os aspectos produtivos, sociais e pessoais das mesmas.

No período da pesquisa, 42 mulheres residiam no PDS Virola Jatobá e destas foi retirada a amostra de $18,{ }^{8} \mathrm{Com}$ as quais foram realizadas entrevistas ${ }^{9}$ a partir de questionários semiestruturados, que consistiam de perguntas abertas e fechadas, explorando informações como: a) Histórico e composição familiar; b) Atividades produtivas e economia; c) Representação social e busca de oportunidades; d) Divisão do trabalho e escoamento da produção (agrícola e não agrícola).

\footnotetext{
6 "A prática da observação participante possibilita maior aproximação e convivência, como conversas informais com as quais é possível compreender a dinâmica local da vida das famílias, de suas formas de organização e cultura" (Josilene Ferreira MENDES, 2012, p. 44).

7 "A observação direta pode visar a uma descrição "fina" dos componentes de uma situação: os sujeitos em seus aspectos pessoais e particulares, o local e suas circunstâncias, o tempo e suas variações, as ações e suas significações, os conflitos e a sintonia de relações interpessoais e sociais, e as atitudes e os comportamentos diante da realidade" (Antonio CHIZZOTI, 2003, p. 90).

${ }^{8}$ Todas as entrevistadas chegaram após a oficialização do PDS. Não foi intenção da pesquisa uma amostragem probalística de significância estatística, mas uma amostragem que pudesse refletir maior proximidade com a realidade vivenciada pelas mulheres no PDS.

9 Segundo Chizzotti (2003), "entrevista é uma comunicação entre dois interlocutores, o pesquisador e o informante, com a finalidade de esclarecer uma questão" (p. 45). A entrevista pode ser livre, estruturada ou semiestruturada. Na primeira hipótese o entrevistado discursa sobre o assunto da forma como quiser; na segunda, responde sobre questões específicas; e na terceira hipótese o discurso é livre e orientado por perguntas-chave.
}

4 Revista Estudos Feministas, Florianópolis, 26(1): e42742 


\section{Relações de gênero e atuação feminina nas unidades de produção agrícola familiares do PDS Virola Jatobá}

Os lotes do PDS possuem 100 ha, onde 20 ha são liberados para uso na agropecuária e 80 ha destinados à Reserva Legal coletiva. ${ }^{10}$ Cerca de $44 \%$ dos lotes são explorados há mais de 10 anos e as atividades principais são as culturas anuais e perenes. Os sistemas de cultivo nas propriedades em estudo são bem diversificados, comportando espécies como arroz (Oryza sativa L.), mandioca (Manihot esculenta Crantz), feijão (Phaseolus vulgaris L.), milho (Zea mays L.), abóbora (Cucurbita spp), pimenta do reino (Piper nigrum L.) e frutíferas como cacau (Theobroma cacao L.), abacaxi (Ananassativus), banana (Musa sp) e cupuaçu (Theobromagrandiflorum), sendo que a maior parte da produção é destinada ao consumo das famílias.

Nenhuma das famílias contrata mão de obra permanente. A divisão do trabalho entre os membros familiares ocorre de acordo com o tipo de cultivo. Diante dessa afirmativa, $22 \%$ das mulheres participam de todas as etapas de produção (do preparo da terra à comercialização do produto final), enquanto que $66 \%$, incluindo estas, participam ativamente do processo na época da colheita, onde todos na família, inclusive as crianças de ambos os sexos, são convocados ao trabalho de acordo com a idade e a capacidade de cada um. Outros $12 \%$ das mulheres são considerados 'ajudantes' nas épocas de semeadura e tratos culturais, pois nessas famílias são os esposos, filhos mais velhos, genros ou pessoas contratadas que realizam os trabalhos 'pesados' de limpeza e preparo.

Mesmo sendo considerado pesado e cansativo, podemos destacar o cultivo da mandioca como sendo um dos principais em que o trabalho da mulher pode ser visto em todas as etapas, desde o plantio, beneficiamento, fabricação e comercialização da farinha. É muito comum que o cultivo de frutas (cupuaçu, acerola, abacaxi) para a produção de polpas também seja realizado pelas mulheres, visto que servem de matéria-prima para a fabricação de bolos, sucos e biscoitos que são vendidos visando à complementação da renda familiar.

Além dos trabalhos na roça e domésticos, as mulheres também são responsáveis pelo cultivo de ervas medicinais, frutas e hortaliças nos quintais agroflorestais ${ }^{11}$ de suas propriedades, onde o trabalho é realizado em parceria ora com os filhos (limpeza e rega), ora com os esposos (poda e replantio). As ervas medicinais cultivadas nesses quintais são de grande importância para as famílias que, devido ao difícil acesso a postos de saúde, trocam experiências e saberes na fabricação de xaropes, chás, emplastros, dentre outros remédios caseiros. Esse conhecimento é transmitido entre gerações, conservando o conhecimento tradicional e conservando a biodiversidade local, como aponta Tatiane Braga FERREIRA (2009) em seus estudos sobre o tema.

Evidencia-se assim a importância das mulheres na conservação da biodiversidade e repasse dos conhecimentos produtivos, uma vez que a atividade nos quintais agroflorestais se configura em um ambiente de repasse de conhecimentos e tradições herdadas de suas

\footnotetext{
10 "A Reserva Legal é uma área protegida por lei, localizada no interior de uma propriedade ou posse rural, cuja vegetação nativa não pode ser derrubada totalmente, mas pode ser usada para fins produtivos, como para produção de frutas, criação de abelhas, artesanato, turismo e manejo seletivo de madeira, porém, não pode ser utilizada para agricultura ou pecuária que impeçam a regeneração da floresta" (Liliane LACERDA, 2009, p. 12).

${ }^{11}$ Quintais agroflorestais se referem ao espaço do terreno ao redor das casas onde são cultivadas diversas espécies vegetais, frutíferas e medicinais que têm como função colaborar com a segurança alimentar, saúde e necessidades básicas de pequenos produtores e suas famílias como também na alimentação e criação de pequenos animais (Tatiane Braga FERREIRA, 2009).
} 
mães e, atualmente, essas mulheres - ao realizarem a mesma prática-continuam a repassar o seu conhecimento sobre a tarefa para seus filhos e filhas, como já mencionado.

Das agricultoras entrevistadas, somente uma desenvolve a olericultura como principal atividade com interesse comercial. Em sua propriedade, o trabalho da mulher se destaca nos tratos culturais (limpeza e rega), na colheita e comercialização. Nesse caso é a própria agricultora quem transporta a produção das hortaliças, por meio de uma motocicleta, para a cidade de Anapu, onde são comercializadas. Nas demais propriedades, as hortaliças cultivadas nos quintais agroflorestais são utilizadas somente para o consumo de suas famílias. No entanto, a comercialização de outros produtos agropecuários como cacau e farinha é realizada quase que exclusivamente pelos esposos ou filhos mais velhos, apresentando somente uma porcentagem de $34 \%$ de mulheres que participam desse processo.

Apenas $16 \%$ das famílias estudadas contratam mão de obra temporária para os trabalhos mais pesados - como o preparo da terra e a formação de pastagens. Com exceção das 'necessidades especiais de mão de obra', pôde-se observar que as outras atividades no estabelecimento são realizadas praticamente pelas famílias. Geralmente mulheres, adolescentes e crianças participam do processo de cultivo, desde a semeadura até a colheita, porém, em casos em que as mulheres não têm filhos solteiros para prestarem essa 'ajuda', elas mesmas realizam todo o trabalho.

De forma geral, na atividade produtiva relacionada ao sistema de cultivo, apenas $12 \%$ de todas as mulheres se consideram como 'ajuda', evidenciando que a maior parte delas $(88 \%)$ se vê como trabalhadora ao participar de todas as etapas do processo produtivo. Esse fato ocorre porque as famílias, nas últimas décadas, estão se modificando, inclusive na forma de pensar, em virtude das transformações na configuração de algumas famílias que não se orientam mais por um modelo exclusivo patriarcal, onde o homem, geralmente considerado o chefe da família, é detentor das decisões e ações produtivas e de comercialização. O que se visualiza no PDS Virola Jatobá é a construção de um cenário de contraposição a este modelo, uma vez que as mulheres, em certos casos, assumem o papel de chefia das famílias em um movimento que faz com que ganhem espaço e reconhecimento em diversas áreas da sociedade, inclusive no meio rural, conforme aponta Nelson Russo de MORAES et al. (2011) em seus estudos.

Em relação ao sistema de criações, evidenciou-se que as pequenas criações de aves e suínos são de pouca relevância no ponto de vista financeiro, mas são importantes fontes de proteínas na alimentação das famílias, sendo comercializadas somente em casos de necessidade financeira. Os cuidados dispensados às criações (alimentação e limpeza das instalações) são de cunho feminino, não impedindo, porém, que os filhos ainda crianças, adolescentes e jovens participem na execução e acompanhamento dos mesmos. Nas famílias que possuem gado leiteiro, ${ }^{12}$ a vacinação e a ordenha dos animais são realizadas pelos esposos ou pelos filhos mais velhos, porém as mulheres realizam essa tarefa caso nenhum deles se encontre na propriedade.

Podemos analisar esse cenário sob a perspectiva de Boni (2006), que destaca que nas propriedades rurais há, socialmente, uma clara divisão do trabalho, ficando com o homem o papel de "chefe da família" e de responsável pela unidade de produção e cabendo à mulher um papel secundário nesta organização - mesmo realizando as mesmas tarefas do marido. A mesma assertiva cabe também às atividades exercidas no sistema de

\footnotetext{
${ }^{12}$ De acordo com o Plano de Uso do PDS, cada família tem direito à implantação de 5 ha de pastagem com suporte de no máximo 8 (oito) cabeças por unidade familiar para a criação de gado de leite com a finalidade de complementar a alimentação e a renda, no caso da venda de queijos e outros subprodutos do leite, e a venda de animais que excederem a capacidade de suporte da pastagem (BRASIL, 2004, p. 6 [no prelo]).
}

6 Revista Estudos Feministas, Florianópolis, 26(1): e42742 
cultivo, embora se tenha evidenciado forte participação das mulheres em todas as fases produtivas.

Sobre as atividades do sistema extrativista, mesmo o PDS sendo uma modalidade de assentamento agroextrativista, nas famílias das mulheres entrevistadas o extrativismo é realizado apenas para o consumo familiar. Dos produtos da floresta, fazem parte da alimentação dessas famílias o açaí (Euterpe oleracea Mart.), a castanha do Brasil (Bertholletia excelsa Bonpl.) e animais como a paca (Cuniculus paca), o tatu-peba (Euphractus sexcintus) e o jabuti (Geochelone carbonária). Todo o trabalho de caça, coleta e apanha é de responsabilidade masculina, cabendo à mulher o processo de preparação/ beneficiamento dos alimentos coletados, revelando, assim como demonstrado por Heredia (1979), ${ }^{13}$ a casa como região de domínio feminino e local de consumo.

\subsection{Atividades anexas e rendas extras: "a visibilidade econômica das mulheres"}

Além das atividades produtivas, as mulheres entrevistadas dispõem também de rendas provenientes de atividades anexas. Esse tipo de atividade, conforme analisam Carlos GUANZIROLI, Antônio Márcio BUAINAIN e Ademar R. ROMEIRO (2003), é recorrente para boa parte das pessoas ocupadas na agricultura familiar, as quais dependem de pensões, aposentadorias, vendas de serviços em outras propriedades ou de atividades não agrícolas. Das agricultoras entrevistadas no PDS, apenas $12 \%$ não recebem nenhum tipo de benefício, enquanto que $66 \%$ afirmaram que recebem o benefício Bolsa Família, 1 \% são aposentadas e $11 \%$ são pensionistas.

Segundo dados do Ministério de Desenvolvimento Social e Combate à Fome (MDS), o Programa Bolsa família atendeu, em 2016, 13.847.958 famílias em todo o país (BRASIL, 2016), sendo que em mais de $95 \%$ delas os titulares dos benefícios são mulheres. Esses recursos auxiliam na aquisição de alimentos, material escolar e roupas para as crianças - 0 que complementa a renda familiar e contribui para a segurança alimentar dessas famílias. De acordo com pesquisa apresentada ao MDS e ao Departament for International Development (DFID), coordenada pela organização não governamental (ONG) brasileira 'Ações de Gênero, Cidadania e Desenvolvimento' (AGENDE), em 2006, a participação nesse tipo de programa elevou a autoestima e o status das mulheres, permitindo-lhes uma posição vantajosa em relação aos outros membros da família cujos empregos e salários são incertos. Na mesma medida, esses recursos possibilitaram, segundo elas, aumento na renda no poder de compra, de escolhas e, principalmente, de negociar sua autoridade no âmbito doméstico (BRASIL, 2008).

\footnotetext{
${ }^{13}$ Heredia (1979) observou que todos os membros de uma família de agricultores da Zona da Mata pernambucana desenvolviam alguma espécie de atividade agrícola, porém os homens quase sempre afirmavam que mulheres e crianças não trabalhavam. Apesar de as mulheres realizarem diversos tipos de atividades que auxiliam na manutenção das unidades de produção familiares, socialmente prevalecia a visão de que os homens são responsáveis por prover as necessidades familiares, enquanto as mulheres se delimitam aos cuidados com a casa e as crianças. Esta autora destaca ainda que a importância dada ao trabalho ocorre a partir da delimitação dos ambientes de produção e de consumo. A oposição entre trabalho e não trabalho se torna mais nítida a partir da distribuiccão das tarefas e do lugar em que ocorrem, evidenciando os papéis feminino e masculino nessa divisão. O homem, ao assegurar o abastecimento dos meios necessários para o consumo familiar, tem seu trabalho mais valorizado socialmente. Enquanto as mulheres e crianças, por fazerem parte do ambiente de consumo, não são considerados trabalhadores. Percebeu, assim, que nem todas as atividades são qualificadas pelas famílias como trabalho, somente aquelas desenvolvidas no roçado (ambiente de produção) recebem esta qualificação. O roçado é visto como domínio masculino, local onde se produz bens essenciais para o consumo familiar; e a casa, de domínio feminino, é onde os produtos do roçado são utilizados para o consumo da família.
} 
Das mulheres entrevistadas, $44 \%$ trabalham em serviços públicos (servente, microscopista e agente de saúde) e autônomas (comerciantes e consultoras Avon). Quanto à representatividade econômica, $56 \%$ das entrevistadas destacaram que contribuem com $50 \%$ na renda mensal familiar; $11 \%$ delas com $75 \%$; $11 \%$ com $30 \%$; $11 \%$ com $25 \%$ e $11 \%$ destacaram ser responsáveis por $100 \%$ da renda de suas famílias, pois são viúvas e sustentam-nas sozinhas. Estes números evidenciam a representatividade financeira e a importância feminina para a reprodutibilidade dos estabelecimentos familiares estudados no PDS Virola Jatobá.

Como outras rendas encontram-se os trabalhos artesanais, fruto dos cursos e capacitações oferecidas pelo Serviço Nacional de Aprendizado Rural (SENAR), a Empresa Brasileira de Pesquisa Agropecuária (EMBRAPA), a Universidade Federal do Pará (UFPA) e o Instituto de Desenvolvimento Sustentável da Amazônia (INDESAM). Dentre os cursos ofertados, os que receberam mais destaque e aceitação pelo grupo de mulheres devido à importância financeira para a renda familiar foram: produção de biscoitos, doces, queijos, compotas, manipulação de alimentos, manejo de açaizais nativos, ${ }^{14}$ crochê, pintura em tecido e fabricação de biojóias (joias produzidas com sementes da floresta).

Segundo José GRAZIANO DA SILVA, Otávio Valentim BALSADI e Mauro Eduardo DEL GROSSI (1997, p. 57), o artesanato que sempre esteve presente na vida das populações rurais e é transmitido através das gerações servia apenas como "hobbies pessoais" e para consumo interno. Agora passa a ser comercializado, tornando-se uma alternativa de emprego e renda no meio rural. No PDS Virola Jatobá essa alternativa sempre foi impulsionada pela oferta de cursos de capacitação pelas empresas de assistência técnica que lá atuam, como o INDESAM e instituições parceiras (INCRA/UFPA/SENAR) ${ }^{15}$ que fornecem instrutores, materiais didáticos e a alimentação durante os períodos de duração dos cursos.

Atualmente os trabalhos artesanais são realizados individualmente ou em equipe, no Grupo de Mulheres do Virola Jatobá (GRUMVIJA), o qual surgiu da necessidade financeira e de busca por qualificação profissional de seus trabalhos, visando à agregação de maior valor aos produtos fabricados por elas. Constituído em 13 de julho de 2009, o GRUMVIJA formalizou o pequeno grupo de mulheres - já existente no PDS $^{16}$ - que necessitavam de organização e apoio financeiro. A ajuda surgiu de um grupo de pesquisadoras alemãs e, entre elas, Eve Brathman, ${ }^{17}$ que trouxe para o PDS um projeto de beneficiamento de sementes

\footnotetext{
${ }^{14}$ Atualmente são as próprias agricultoras que realizam o manejo em suas Unidades de Produção Familiares no PDS.

${ }^{15}$ Geralmente os cursos que são realizados no PDS partem da identificação de possíveis demandas a serem atendidas. Assim, são realizadas parcerias interinstitucionais para tentar garantir o atendimento das mesmas. Contudo, em virtude de problemas de ordem administrativa, logística e financeira, nem sempre os resultados posteriores à realização dos cursos têm como serem acompanhados, o que se configura como uma limitação no atendimento realizado pelas instituições, tendo reflexo tanto para as mesmas, que desconhecem quantitativa e qualitativamente os resultados de suas ações, quanto para as populações atendidas, que ficam sem assistência posterior ao curso e, consequentemente, sem possibilidade de complementação em sua capacitação - em alguns casos.

${ }^{16}$ Antes de sua formalização, o GRUMVIJA era conhecido como "Guerreiras do Virola". Este grupo informal reunia mulheres que trocavam conhecimentos artesanais e realizavam ajuda mútua entre as famílias da comunidade. O nome "Guerreiras do Virola" estava associado à luta por ideais comuns das mesmas dentro do PDS, como a busca por infraestrutura para reuniões e local propício para a fabricação dos artesanatos, possibilidade de comercialização e escoamento dos produtos fabricados etc.

${ }_{17}$ Brathman serviu como bolsista da Fulbright no Brasil em 2006-2007, onde trabalhava em sua pesquisa de campo de doutorado em uma região de fronteira da Amazônia. Atualmente é pesquisadora visitante da Comissão Pastoral da Terra (CPT) e da Fundação Viver, Produzir e Preservar (FVPP) em Altamira, Pará, Brasil. Brathman é também pesquisadora afiliada ao Instituto de Pesquisas Ambientais da Amazônia (IPAM) (Belém Brasil), e Uni Euro (Brasília, Brasil).
}

8 Revista Estudos Feministas, Florianópolis, 26(1): e42742 
e confecção de biojóias. O grupo reunia agricultoras com a missão e o objetivo de fortalecer o PDS na geração de emprego e renda com sustentabilidade e com o uso adequado e consciente dos recursos encontrados por elas na comunidade.

Em relação aos artesanatos produzidos, das entrevistadas, $44 \%$ informaram que obtêm uma renda extra proporcionada a partir da venda, $38 \%$ informaram que produzem artesanato somente para o próprio consumo e $18 \%$ não praticam nenhuma atividade artesanal. Dentre os produtos mais confeccionados e comercializados estão os panos de prato, jogos de crochê, flores de EVA ${ }^{18}$ (Etil Vinil e Acetato), bonecas de lã e fitas, biojóias, quadros com sementes e bordados.

A comercialização dos produtos artesanais é realizada, predominantemente, de forma direta ao consumidor com a exposição de peças em eventos realizados no PDS, como torneios de futebol, festas juninas, comemorações dos dias das mães, dos pais e das crianças ou outras datas comemorativas e, até mesmo, durante reuniões com as instituições parceiras já citadas, sendo as próprias mulheres as responsáveis pelo escoamento da produção daquilo que fabricam, confeccionam e/ou beneficiam. Das entrevistadas, 78\% possuem motocicleta própria, o que proporciona rapidez na comercialização dos produtos na venda "porta a porta". Essa diversificação das atividades demonstra que a pluriatividade ${ }^{19}$ vem ganhando força no meio rural entre os pequenos agricultores, diversificando as fontes de renda e dando oportunidades profissionais a todos os indivíduos da mesma família (Sérgio SCHNEIDER, 2003).

As mulheres entrevistadas não visualizam ainda grandes mudanças financeiras oriundas da comercialização dos produtos que fabricam, uma vez que a produção dos mesmos ainda é pequena e as condições financeiras para a produção em maior escala são baixas. Contudo, as entrevistadas afirmam que estão evoluindo nesse sentido, se sentindo mais autonômas financeiramente. Com a renda extra obtida elas compram itens de consumo e materiais escolares para os filhos, além de produtos para a fabricação de novos itens artesanais. Assim, as mulheres têm nessas atividades uma fonte de renda cada vez mais significativa para suas famílias. Esse fato é relatado nos estudos de Araguacy Paixão Almeida FILGUEIRAS (2005), que afirma que "o artesanato promove a inserção da mulher e do adolescente em atividades produtivas, estimulando a prática do associativismo e fixando o artesão no local de origem" (p. 21).

\subsection{A organização coletiva e a busca pela ascensão feminina no PDS Virola Jatobá}

Além do GRUMVIJA, existem outras duas organizações coletivas no PDS: a Cooperativa de Produtores Agrícolas Orgânicos e Florestais do PDS Virola Jatobá (COOPAF), fundada em 24 de abril de 2007, e a Associação Virola Jatobá (AVJ), ${ }^{20}$ fundada em 22 de janeiro de 2003. 78\% das mulheres entrevistadas participam das duas. A AVJ tem contribuído para o desenvolvimento econômico e social da localidade, cedendo o barracão da associação

\footnotetext{
${ }^{18}$ Conhecido entre artesãos e artistas como EVA, o Etil Vinil Acetato é uma borracha não tóxica que pode ser aplicada em diversas atividades artesanais.

19 "Situações sociais em que os indivíduos que compõem uma família com domicílio rural passam a se dedicar ao exercício de um conjunto variado de atividades econômicas e produtivas, não necessariamente ligadas à agricultura ou ao cultivo da terra, e cada vez menos executadas dentro da unidade de produção" (Sérgio SCHENEIDER, 2003, p. 100).

${ }^{20}$ Ressalta-se que no PDS Virola Jatobá configuram-se dois processos de organização coletiva, o associativismo e o cooperativismo, sendo que as mulheres entrevistadas participam de ambos. Contudo, os dois processos e os resultados prospectivos relacionados aos mesmos ainda não são mensurados de forma efetiva, uma vez que tanto o associativismo quanto o cooperativismo estão em construção, necessitando de assimilação (experiência) por parte das mulheres que o praticam e maturação enquanto processos que podem vir a ter resultados que viabilizem o desenvolvimento local, especialmente vinculados ao empoderamento feminino.
} 
para a realização dos cursos e oficinas de capacitação para homens e mulheres, oferecendo assim mais oportunidades para as categorias locais. Nesse sentido, Rosana Marcela SCHMIDT et al. (2005) reforçam que "o associativismo nasceu junto com o homem, e provém da necessidade da união para vencer os desafios do mundo" (p. 16), exigindo esforço coletivo e que todos operem conjuntamente.

Como prova da ascensão da representatividade social da mulher em meio à comunidade, podem-se citar as eleições para a escolha da diretoria da AVJ para o ano de 2015, em que os representantes escolhidos para os principais cargos são todas mulheres. Antes disso, as mulheres ocupavam cargos de menor representatividade e visibilidade hierárquica nas organizações sociais locais. A atual gestão é composta por uma presidente, uma secretária e uma tesoureira, demonstrando, portanto, o reconhecimento e a confiabilidade dos 118 sócios (entre homens e mulheres) na competência do trabalho das mulheres. Ressalta-se que o direito ao voto nas eleições da AVJ é condicionado a todos os sócios e sócias que estejam com suas mensalidades (taxa simbólica) em dia, ou que tenham negociado sua dívida perante a Associação.

Na perspectiva de dias melhores, as agricultoras têm acumulado experiências de práticas artesanais associadas às atividades domésticas e agropecuárias. Elas geram renda e conhecimentos a partir da venda de seus produtos, contribuindo para o fortalecimento econômico e social do grupo de mulheres do PDS no qual cada uma delas é responsável por uma ou mais atividades artesanais. Durante os diálogos informais com as agricultoras sobre a origem do grupo de mulheres, elas informaram que, no início, o trabalho era realizado individualmente ou em duplas para superar a solidão nos horários em que os esposos estavam na roça e os filhos frequentavam a escola. Este foi fator/incentivo para a criação do grupo, quando, por iniciativa própria, elas decidiram se unir e produzir de forma solidária. A consolidação das atividades do GRUMVIJA ocorreu por meio dos cursos oferecidos por instituições parceiras, resultando na socialização não somente do grupo, mas de toda a comunidade.

Com o passar do tempo surgiram dificuldades na confecção das biojóias; entre elas, o manuseio do equipamento de perfuração das sementes e dificuldades na comercialização das peças. Assim, a falta de recursos financeiros para a garantia da continuidade do projeto acarretou a paralização do mesmo. Para que não ficasse totalmente estagnado, houve uma reestruturação de atividades e atualmente o trabalho do grupo que reúne, aproximadamente, 17 mulheres (todas participantes da amostra de entrevistadas), está focado somente na produção de peças artesanais relacionadas à pintura em tecido, crochê e à produção de biscoitos.

Em relação à produção de biscoitos, há uma possibilidade de um futuro promissor quanto à comercialização e os ganhos que poderiam advir com ela. Trata-se de uma atividade incentivada por instituições parceiras por meio da capacitação profissional e disponibilização de equipamentos para a produção. A produção, no entanto, tem sido inconstante, uma vez que é de dífícil gestão por parte das mulheres em decorrência da realização simultânea de múltiplas atividades. Assim, atualmente, tanto a fabricação quanto a comercialização de biscoitos está sob responsabilidade de apenas uma integrante do GRUMVIJA (que não divide os lucros com as demais e nem as mesmas se manifestam quanto à situação por não participarem da fabricação, apesar dos equipamentos pertecerem a todo o grupo). Esse cenário evidencia que as mulheres, provavelmente, ainda não visualizaram o potencial dessas atividades e do auxílio financeiro que poderia vir a complementar suas rendas a partir da comercialização dos produtos, sendo esta uma perspectiva que precisa de maturação por parte das integrantes do GRUMVIJA.

10 Revista Estudos Feministas, Florianópolis, 26(1): e42742 
No entanto, as mulheres não produzem apenas artesanatos; elas também produzem relações sociais através de um trabalho que elas conhecem, dominam, executam e sentem orgulho e prazer em desenvolver por se tratar de um trabalho criativo e artístico, sendo que o mais importante é a geração de renda extra. Este cenário pode ser analisado segundo a perspectiva de Schmidt et al. (2005), que destacam que, segundo a experiência dos pioneiros da prática cooperativista de Rochdale, ${ }^{21}$ é possível a união das pessoas em torno de um objetivo, e que a organização de uma cooperativa pode melhorar a situação econômica, social e as condições de vida de uma comunidade cooperativada.

Compartilhando dos mesmos objetivos e sonhos, as mulheres do GRUMVIJA unem forças para vencer os desafios que, individualmente, seriam incapazes de superar. Um dos desafios que está em fase de planejamento em parceria com o INCRA e o INDESAM é o projeto para a construção de um prédio no próprio PDS - onde será a sede do GRUMVIJA. Dessa forma, as mulheres terão espaço para as atividades artesanais (crochê, bordado e pintura) e uma cozinha agroindustrial onde poderão fabricar seus doces, biscoitos, beneficiamento de frutas (polpas), além de, consequentemente, ampliarem as chances de uma comercialização certificada.

A participação no grupo proporcionou às mulheres entrevistadas a criação de um espaço para mostrar à comunidade o que elas são capazes de produzir e a forma como produzem - mesmo diante das dificuldades. As conversas informais demonstraram que elas têm consciência da visibilidade e da contribuição que seu trabalho tem dentro e fora de suas propriedades. Por esta razão, nas reuniões das instituições parceiras para a elaboração de calendário de trabalho, elaboração de projetos e oficinas de avaliação dos trabalhos semestrais e anuais, elas sempre se fazem presentes, obtendo participação expressiva em relação aos homens.

Embora as mulheres participem efetivamente das organizações coletivas do PDS, em alguns casos obtendo rendas extras a partir dessa união, adquirindo certa autonomia, elas ainda não podem ser consideradas, do ponto de vista financeiro, emancipadas. Há esse interesse por parte das entrevistadas, mas, em virtude das baixas condições financeiras das famílias, da produção dos artesanatos ainda ser em pequena escala, da falta de apoio de instituições públicas, além do escoamento dos produtos ser dificultado pelas condições logísticas e distância dos centros urbanos, ainda não é possível afirmar que conseguirão progredir nesse sentido. Contudo, demonstram perseverança e vontade em continuar evoluindo por meio da união e da ocupação nos mais diversos espaços.

Em datas comemorativas como o dia das mães, dia dos pais e dia das crianças, as mulheres têm participação significativa no planejamento, preparação e execução dos eventos. A ornamentação, alimentação, homenagens, brindes e brincadeiras são de responsabilidade delas que, em parceria com instituições (AVJ, Igreja, INCRA e INDESAM), fazem tudo - segundo as próprias entrevistadas - com muito carinho e dedicação.

Existe uma grande proximidade entre as famílias no PDS. Quando questionadas sobre a relação com a comunidade, elas afirmaram que existe uma boa convivência entre as famílias e que raramente ocorrem conflitos. No campo religioso, 50\% das entrevistadas são evangélicas e $50 \%$ são católicas. Entretanto, a convivência e os laços de afeto independem da religião ou de poder aquisitivo dessas famílias, que compartilham de objetivos comuns como a melhoria das condições de vida, trabalho, estudo, cultura e lazer na comunidade. Sobre essa relação pacífica, ao conquistarem os objetivos almejados, as pessoas se sentem estimuladas, o que aumenta a confiança entre elas "e, um objetivo que,

${ }^{21}$ Rochdale, bairro de Manchester-Inglaterra, ano de 1844. "Conhecida como a primeira cooperativa moderna do mundo. Ela criou os princípios morais e a conduta que são consideradas, até hoje, a base do cooperativismo autêntico". 
inicialmente, parecia ser difícil de realizar sem a ação coletiva, passa a ser percebido como uma conquista do grupo" (SENAR, 201 1, p. 12) das entrevistadas - cenário este que se aproxima da realidade estudada no PDS Virola Jatobá.

\section{Considerações finais}

As mulheres do PDS Virola Jatobá, através de sua união, estão buscando a ruptura de uma construção social que as trata como "ajuda" e, pouco a pouco, tendo o seu trabalho reconhecido e valorizado pela comunidade onde vivem. Entretanto, a luta pela valorização feminina no meio rural ainda é inicial, pois na sociedade - até este momento - se encontra enraizado um padrão de dominação e exploração masculina e com poucas alternativas de participação econômica e política para as mulheres. As relações de gênero ainda são fortes e se perpetuam na divisão de tarefas, do trabalho e na desvalorização econômica da mulher.

Nessa conjuntura, as mulheres do PDS Virola Jatobá atuam em busca de reconhecimento do seu trabalho nas atividades produtivas enquanto fator gerador de renda, sendo esta de fundamental importância para o bom funcionamento e reprodutibilidade das unidades de produção familiares. Além disso, as mesmas se multiplicam em diversas funções - que vão desde atividades produtivas, manutenção da biodiversidade (no caso dos quintais agroflorestais), atividades anexas, rendas extras, cuidados com os filhos e engajamento social -, o que evidencia que estão buscando espaço e inserção nos mais diversos cenários. Desse modo, o reconhecimento da representatividade feminina nas unidades familiares estudadas se revela de extrema importância não somente devido aos aspectos econômicos, essenciais para sustentabilidade de suas famílias, mas porque essas mulheres se fazem representar em outras ocupações dentro e fora das suas propriedades, como é caso da AVJ, organização a qual atualmente estão à frente, e o GRUMVIJA.

Apesar de a pesquisa ter revelado a representatividade da mulher enquanto "participação ativa" na geração de renda familiar, diferenciando-se dos modelos em que as mulheres eram vistas somente como "ajudantes", não é apenas com a valorização da autoestima da classe feminina que os obstáculos serão superados e os objetivos alcançados. A permanência dessas mulheres e suas famílias no meio rural necessita de melhores e maiores investimentos em projetos elaborados especificamente para elas, e também do envolvimento de toda a comunidade na realização dos mesmos, melhorando assim a qualidade de vida no PDS, o que é o principal sonho delas. É necessário que haja uma qualificação cada vez melhor das atividades produtivas já desenvolvidas. Com estes projetos realizados, elas terão seus horizontes ampliados e poderão aprimorar as atividades que já desenvolvem na comunidade, fincando suas raízes no campo, não havendo, dessa forma, necessidade de deixá-lo para ir morar na cidade em busca de melhores condições de vida.

Com as informações obtidas nesta pesquisa, pretende-se contribuir para a ampliação do conhecimento acadêmico e reflexões acerca do papel desempenhado pelas mulheres agricultoras em suas comunidades, o que pode servir de base para propostas de políticas públicas para atendimento de demandas de equidade e gênero.

\section{Referências}

ARNAULD DE SARTRE, Xavier et al. "O "Bom" Casamento em Áreas de Fronteira ou a Difícil Autonomização das "Tarefas" Femininas em Área de Fronteira". In: NEVES, Delma Pessanha; MEDEIROS, Leonilde Servolo de (Orgs.). Mulheres camponesas: trabalho produtivo e engajamentos políticos. Niterói: Alternativa, 2013. p. 107-128.

12 Revista Estudos Feministas, Florianópolis, 26(1): e42742 
BONI, Valdete. "Gênero: o doméstico e o produtivo na agroindústria familiar". In: CONGRESSO LATINO-AMERICANO DE SOCIOLOGIA RURAL, 7., 2006, Equador. Anais... Equador, 2006. p. 38-39.

BRASIL. Instrução normativa n. ${ }^{\circ}$ 38, de 13 de março de 2007. Dispõe sobre as normas do INCRA para efetivar o direito das trabalhadoras rurais ao Programa Nacional de Reforma Agrária. Diário Oficial [da] República Federativa do Brasil, Poder Executivo, Brasília, DF, 14 de março de 2007. Seção I, p. 57.

Presidência da República. VI Relatório Nacional Brasileiro: Convenção pela Eliminação de todas as Formas de Discriminação contra as Mulheres - CEDAW/ Organizações das Nações Unidas. Brasília: Secretaria Especial de Políticas para as Mulheres, 2008. 98p. (Série Documentos)

Ministério do Desenvolvimento Social e Agrário. Relatórios de Informações Sociais 2016. Disponível em: https://aplicacoes.mds.gov.br/sagi/Rlv3/geral/index.php. . Ministério do Desenvolvimento Agrário e INCRA. Plano de Utilização da Associação do Projeto de Desenvolvimento Sustentável de Anapu, Pará, 2004, 8p. (no prelo).

CASTRO, Roberta Rowsy Amorim de. Comunidades Tradicionais e Unidades de Conservação no Pará: a influência da criação da Reserva Extrativista Rio Xingu - Terra do Meio, nos modos de vida das famílias locais. 2013. Dissertação (Mestrado em Agriculturas Familiares e Desenvolvimento Sustentável) - Programa de Pós-Graduação em Agriculturas Amazônicas, Universidade Federal do Pará, Belém, PA, Brasil.

CHIZZOTTI, Antonio. Pesquisa em ciências humanas e sociais. São Paulo: Cortez, 2003.

CORDEIRO, Rosineide de Lourdes Meira. "Agricultura familiar, trabalho feminino e ação coletiva". In: ENCONTRO NACIONAL DA ASSOCIAÇÃO BRASILEIRA DE PSICOLOGIA SOCIAL, 14., 2007, Rio de Janeiro. Anais... Rio de Janeiro: ABRAPSO, 2007. p. 1-13.

FERREIRA, Tatiane Braga. "Quintais agroflorestais como fonte de saúde: plantas medicinais na Comunidade de Vila Franca, Reserva Extrativista Tapajós-Arapiuns, Pará". Revista Brasileira de Agroecologia, v. 4, n. 2, p. 3159-3162, nov. 2009.

FILGUEIRAS, Araguacy Paixão Almeida. Aspectos socioeconômicos do artesanato em comunidades rurais do Ceará - o bordado de ltapajé. 2005. Dissertação (Mestrado em Economia Rural) - Departamento de Economia Agrícola, Universidade Federal do Ceará, Fortaleza, CE, Brasil.

GALIZONI, Flávia Maria; RIBEIRO, Eduardo Magalhães. "Trabalho feminino na agricultura familiar do Alto Jequitinhonha, Minas Gerais". In: CONGRESSO BRASILEIRO DE ECONOMIA E SOCIOLOGIA RURAL, 42., 2004, Cuiabá. Anais... Brasília: SOBER, 2004.

GRAZIANO DA SILVA, José; BALSADI, Otávio Valentim; DEL GROSSI, Mauro Eduardo. "O emprego rural e a mercantilização do espaço agrário". São Paulo em Perspectiva, v. 11 , n. 2, p. 50-64, 1997.

GUANZIROLI, Carlos; BUAINAIN, Antônio Márcio; ROMEIRO, Ademar R. "Agricultura Familiar e o Novo Mundo Rural". Sociologias, n. 10, p. 312-347, jul./dez. 2003.

HEREDIA, Beatriz Maria Alásia de. A Morada da Vida: trabalho familiar de pequenos produtores no Nordeste do Brasil. Rio de Janeiro: Paz e Terra, 1979.

LACERDA, Liliane. Sistemas agroflorestais: uma alternativa de manter a floresta em pé. Bonito: Centro Gráfico Ruy Babosa; Instituto das Àguas da Serra da Bodoquena, 2009.

MENDES, Josilene Ferreira. O direito vivo na luta pela terra no Projeto de Desenvolvimento Sustentável Virola Jatobá em Anapu/PA. 2012. Dissertação (Mestrado em Agriculturas Familiares e Desenvolvimento Sustentável) - Programa de Pós-Graduação em Agriculturas Amazônicas, Universidade Federal do Pará, Belém, PA, Brasil.

MORAES, Nelson Russo de et al. "O papel da mulher, assumindo o perfil de gestora social diante do desafio da promoção do desenvolvimento sustentável em comunidades 
tradicionais amazônicas: o caso de Dona Derci da Silva (Comunidade Remanescente de garimpos de Cristal, Pequizeiro - TO)". In: ENCONTRO NACIONAL DE PESQUISADORES EM GESTÃO SOCIAL, 5., 201 1, Florianópolis. Anais... Florianópolis: meio digital - website, v. 1, 2011, p. 136-147.

OLIVEIRA, Ariovaldo Umbelino de. Integrar para não entregar: políticas públicas e Amazônia. Campinas: Papirus, 1988.

PARÁ. Lei Estadual no 5.929, de 28 de dezembro de 1995. Dispõe sobre a criação do município de Anapu e dá outras providências. Diário Oficial [do] Estado do Pará nº 28.120, Assembleia Legislativa do Estado do Pará, PA, 29 de dezembro de 1995.

PAULILO, Maria Ignez Silveira. "O peso do trabalho leve". Ciência Hoje, v. 5, n. 28, p. 64-70, jan./fev. 1987.

SAUER, Sérgio. Violação dos direitos humanos na Amazônia: conflito e violência na fronteira paraense. Goiânia: CPT; Rio de Janeiro: Justiça Global; Curitiba; Terra de Direitos, 2005.

SCHMIDT, Rosana Marcela et al. "Cooperativismo, uma alternativa de geração de renda para pequenos e médios produtores rurais". In: SEMINÁRIO NACIONAL ESTADO E POLÍTICAS SOCIAIS NO BRASIL, 2., 2005, Cascavel. Anais... Cascavel, 2005.

SCHNEIDER, Sérgio. "Teoria social, agricultura familiar e pluriatividade". Revista Brasileira de Ciências Sociais, v. 18, n. 51, p. 99-122, fev. 2003.

SENAR - Serviço Nacional de Aprendizagem Rural. Associações rurais: práticas associativas, características e formalização. Brasília: SENAR, 2011.

WANDERLEY, Maria de Nazareth Baudel. "Raízes Históricas do Campesinato Brasileiro". In: ENCONTRO ANUAL DA ASSOCIAÇÃO NACIONAL DE PÓS-GRADUAÇÃO E PESQUISA EM CIÊNCIAS SOCIAIS, 20., 1996, Caxambu. Anais... 1996. Caxambu: ANPOCS, 1996.

WOORTMANN, Ellen F; WOORTMANN, Klaas. O trabalho da terra: a lógica e a simbólica da lavoura camponesa. Brasília: UNB, 1997.

[Recebido em 25/01/2016,

reapresentado em $03 / 11 / 2016$

e aprovado em 13/02/2017]

The Search for Female Ascension in the Virola Jatobá SDP, Anapu-PA

Abstract: This research aimed to analyze the role of women in VirolaJatobáPDS, Anapu-Pará, its importance and representation in productive, economic and social activities and describe how you are giving the search for female ascent through the association. They interviewed 18 women farmers and it was found that these participate in the work processes in farming systems, creations and extraction. With regard to the accompanying activities and extra income, all interviewees contribute to the monthly income of their families. Women PDS exert important collective role, to organize themselves into associations and other gender, highlighting the search for insertion in various scenarios. This action contributes to recognize themselves as workers and not just as helpers.

Keywords: Family Farmers; Women Farmers; Gender Relations; Women's Work

Ana Ruth dos Santos Chaves (chaveshturhta@hotmail.com) é engenheira agrônoma pela Universidade Federal do Pará, Campus Altamira.

Roberta Rowsy Amorim de Castro (roberta_rowsy@hotmail.com) é graduada em Engenharia Agronômica pela Universidade Federal do Pará, Campus de Altamira, e possui Mestrado em Agriculturas Familiares e Desenvolvimento Sustentável. Atualmente é

14 Revista Estudos Feministas, Florianópolis, 26(1): e42742 
professora da Faculdade de Formação e Desenvolvimento do Campo, Universidade Federal do Pará, Campus Abaetetuba.

Andreia de Menezes (deia.portugal@hotmail.com) é engenheira agrônoma, formada pela Universidade Federal do Pará, Campus de Altamira. Possui experiência com assistência técnica e extensão rural. 